\title{
CAN CORTICAL AND WHITE MATTER DEVIATIONS EXPLAIN DEFICITS IN WORKING MEMORY AND PROCESSING SPEED IN VLBW YOUNG ADULTS?
}

\author{
J. Skranes ${ }^{1,2,3}$, G.C. Løhaugen ${ }^{1,2}$, L. Eikenes ${ }^{4,5}$, M. Martinussen ${ }^{1,6}$, A. Håberg ${ }^{5,7}$, A.M. Dale ${ }^{4,8}$, A.-M.
} Brubakk $^{1,3}$

${ }^{I}$ Dept of Lab.Medicine, Children's and Women's Health, Norwegian University of Science and Technology, Trondheim, ${ }^{2}$ Dept of Pediatrics, Sørlandet Hospital HF, Arendal, ${ }^{3}$ Dept. of Pediatrics, St Olav's University Hospital, ${ }^{4}$ Dept. of Circulation and Medical Imaging, Norwegian University of Science and Technology,

${ }^{5}$ Dept. of Diagnostic Imaging, MR Center, ${ }^{6}$ Dept. of Gynecology and Obstetrics, St Olav's University Hospital, ${ }^{7}$ Dept. of Neuroscience, Norwegian University of Science and Technology, Trondheim, Norway, ${ }^{8}$ MIL, Dept. of Neurosciences and Radiology, Univeristy of California, San Diego, CA, USA

Background and aims: Perinatal brain injury in very low birth weight (VLBW) children affecting grey and white matter damage is associated with neurocognitive deficits that persist into adulthood. The aim of study was to investigate the relationship between cognitive deficits and cortical surface area and white matter deviations in VLBW young adults.

Methods: 49 VLBW (birth weight $\leq 1500$ grams) and 59 term born controls were examined at the age of 19 with Wechsler Adult Intelligence Scale WAIS-III and MRI. An automated MRI technique at 1.5 Tesla for morphometric analyses of cortical surface area and DTI to investigate fractional anisotropy in white matter tracts were performed in both groups.

Results: IQ was associated with reduced surface area in specific cortical regions of the brain of the VLBW young adults. The IQ indices that corresponded the most to the associations were the Working Memory Index and the Processing Speed Index (Figure 1). These indices were also related with FA reduction in central white matter tracts like corpus callosum, capsula externa and sup. long. fasciculus.

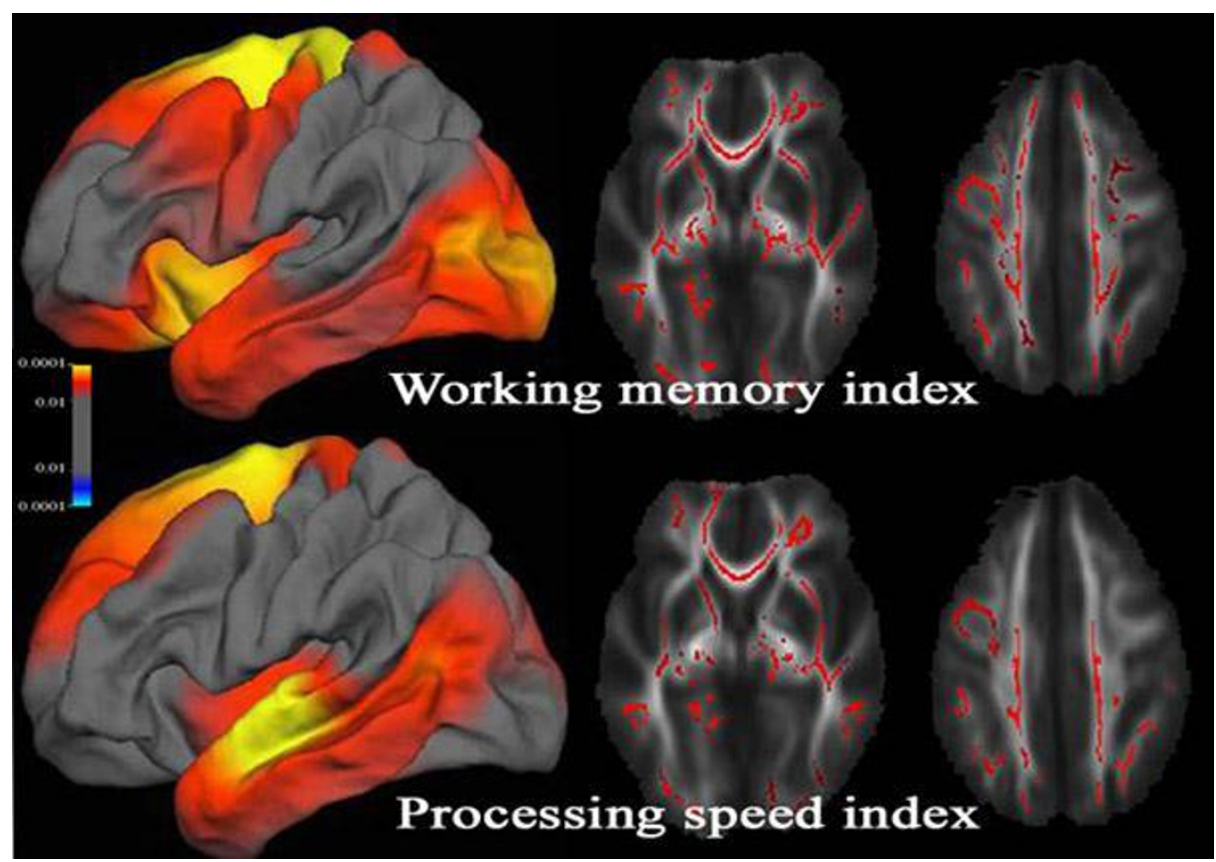

[Figure 1]

Conclusions: Cognitive deficits in young adults born with VLBW were related with both grey and white matter abnormalities indicating perinatal brain injury with permanent consequences for brain development and functioning. 